\title{
Fatal Skin and Soft Tissue Infection, Peritonitis and Bacteriemia Caused by Shewanella petrefaciens
}

\author{
Cynthia Zhao*, Long Jin* \\ Department of Pathology, Louisiana State University Health Sciences Center Shreveport, Shreveport, LA, USA \\ Email: "ljin@Isuhsc.edu, "czhao@Isuhsc.edu
}

Received 26 February 2016; accepted 7 April 2016; published 11 April 2016

Copyright @ 2016 by authors and Scientific Research Publishing Inc.

This work is licensed under the Creative Commons Attribution International License (CC BY).

http://creativecommons.org/licenses/by/4.0/

cc) (i) Open Access

\begin{abstract}
We report a case of skin and soft tissue infection, peritonitis and bacteriemia in a 51-year-old drug abuse male. His wife found him lifeless lying on the kitchen floor at his residence. At the time of autopsy, multiple skin ulcers with deep soft tissue infection and peritonitis were found on gross examination. Cultures of postmortem blood and a swab of soft tissue were positive for Shewanella putrefaciens, a gram-negative bacterium that had been isolated from many foods, sewage and fresh and salt water. This is the first reported case in the United States of fatal skin and soft tissue infection, peritonitis and bacteremia caused by this micro-organism.
\end{abstract}

Keywords

Shewanella putrefaciens, Autopsy, Drug Abuse, Skin Ulcer, Peritonitis

\section{Introduction}

Shewanella putrefaciens is gram-negative, motile bacillus found in various environmental and animal sources, including all forms of water and soil [1] [2]. It is not a common human pathogen and mostly found in a different variety of clinical specimens as mixed flora [1] [3] [4]. In rare instances, it causes wound infection, soft tissue infection, bacteremia, ventilated-associated pneumonia and cerebellar abscess and meningitis [2]-[5]. We report a fatal skin and soft tissue infection, peritonitis and bacteremia caused by Shewanella putrefaciens in a 51-yearold drug abuse male. To date, only six fatal cases caused by Shewanella putrefaciens have been reported in the English literature [6] [7]; none is in the USA.

${ }^{*}$ Corresponding author.

How to cite this paper: Zhao, C. and Jin, L. (2016) Fatal Skin and Soft Tissue Infection, Peritonitis and Bacteriemia Caused by Shewanella petrefaciens. Forensic Medicine and Anatomy Research, 4, 29-32.

http://dx.doi.org/10.4236/fmar.2016.42005 


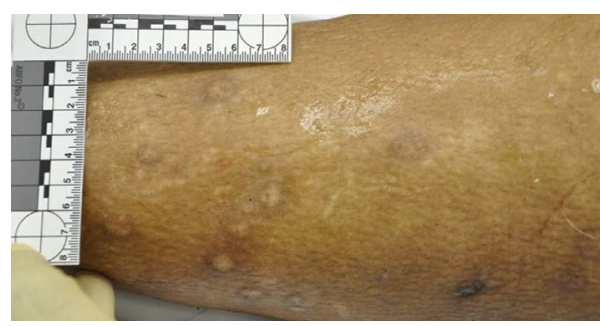

Figure 1. Multiple old scars over the left lower leg due to drug abuse.

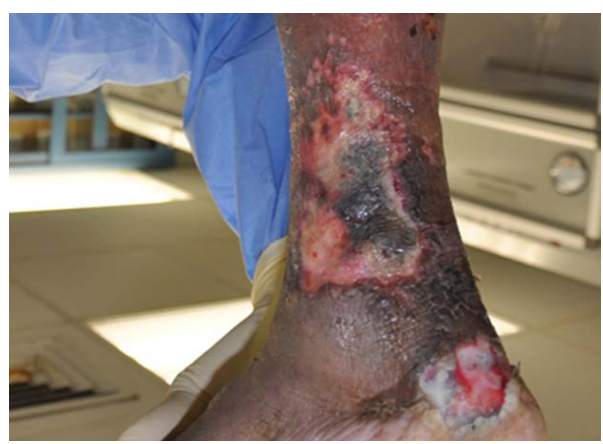

Figure 2. Skin ulcers of different healing ages over the right ankle and foot.

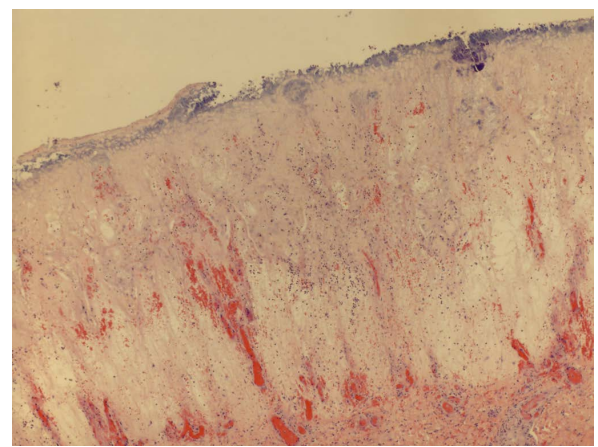

Figure 3. Section of the skin ulcer of the right lower leg revealed denuded squamous epithelium, vascular congestion, marked edema and necrosis ( $\mathrm{H} \& \mathrm{E}, \mathrm{X} 2$ ).

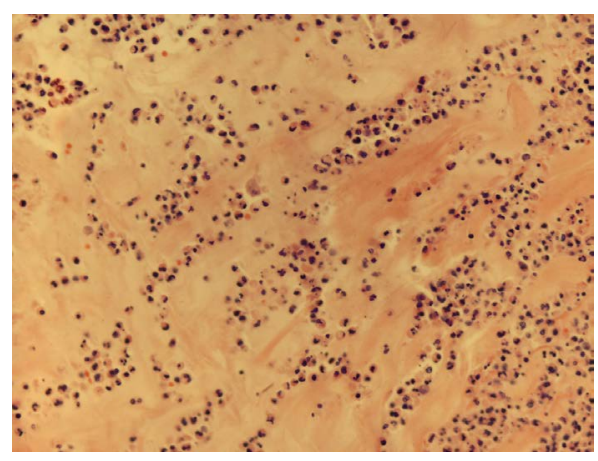

Figure 4. Section of the skin ulcer of the right lower leg revealed extensive acute inflammation in subcutaneous tissue ( $\mathrm{H} \& \mathrm{E}, \mathrm{X} 20$ ). 


\section{Case Report}

The patient was a 51-year-old African American male with a history of drug abuse. He was found lifeless lying on the kitchen floor at his residence by his wife. An autopsy was performed at the Pathology Department of Louisiana State University Health Sciences Center in Shreveport upon being requested by the local Coroner's office. Postmortem external examination found multiple old scars (Figure 1), consistent with history of drug abuse, skin abrasions and ulcers of different healing stages over the lower extremities and back (Figure 2). Upon internal examination, the abdominal cavity contained $3600 \mathrm{ml}$ of cloudy ascites. The capsule of the liver was thickened and fibrotic. Other significant findings included cardiomegaly (500 grams, expected 296 - 376 grams) with concentric hypertrophy of left ventricle, nephrosclerosis and severe luminal stenosis of left anterior descending coronary artery. The representative tissue sections taken from their respective organs were fixed in $10 \%$ neutral buffered formalin (NBF) for a sufficient time period. Standard hematoxylin and eosin (H \& E) stain [8] was performed on the processed paraffin blocks, which contain tissue sections. On microscopy, hematoxylin and eosin (H \& E) sections of the skin ulcer of the right lower leg revealed denuded squamous epithelium, marked edema, necrosis (Figure 3) and extensive acute inflammation in cutaneous and subcutaneous tissue (Figure 4). Sections of myocardium and kidney revealed changes consistent with hypertensive changes. Section of liver revealed chronic inflammation in the capsule and subcapsular parenchyma. Cultures of postmortem blood and a swab of soft tissue were positive for Shewanella putrefaciens with antimicrobial susceptibility of ceftazidime, amikacin, piperacillin/tazobactam, cefepime, gentamicin and ciprofloxacin. The cause of death was determined to be sepsis due to hematogenous spread of Shewanella putrefaciens from multiple skin ulcers.

\section{Discussion}

Shewanella putrefaciens is found predominantly in all forms of water and soil [1] [2] [9]. The majority of the patients who were infected with Shewanella putrefaciens had history of skin injuries that disrupted the integrity of the skin or being contacted with contaminated water [1] [9]. Other predisposing factors include renal failure, malignancy, poor living condition, hepatobiliary disease, alcoholism or immunosuppressive patients [3] [10]. Only six cases of fatal infection of Shewanella putrefaciens have been reported previously in three English publications [6] [7] [11], none in the United States. In the report of Yim et al. [6], the patient had undergone continuous ambulatory peritoneal dialysis (CAPD) for 6 years due to chronic glomerulonephritis and resided near the seacoast of Korea. He developed peritonitis, necrotizing fasciitis of left flank and bacteremia and succumbed to the infection despite appropriate and prompt antibiotic treatment. In the review paper of Vignier et al., two patients died due to skin and soft tissue infection with bacteremia and one patient died due to osteitis with renal failure [7]. Tsai et al. reported that two patient died of septicemia secondary to Shewanella soft tissue infection. One of them was an alcoholic with fatty liver and another patient suffered underlying diseases of hypothyroidism, hypertension and stasis [11].

Multiple skin ulcers caused by either drug use or injuries secondary to falls, which are common in alcoholism, certainly provided a portal for the bacteria to enter, colonize in the wounds and further spread into the blood stream. Drug abuser and alcoholics may result in immunosuppression [12] [13], rendering afflicted patients susceptible to lethal infections by micro-organisms of low virulence, such as Shewanella putrefaciens, on the presence of skin and soft tissue lesions.

Our patient was a known drug abuser, alcoholic and had multiple skin ulcers. As such, he had some predisposing factors for exposure and colonization by water or soil inhabitants, such as Shewanella putrefaciens. Despite its rare occurrence, this unique case highlights an important point regarding this unusual pathogen in drug abusers who are susceptible and vulnerable to all sorts of micro-organisms including low virulences strain secondary to their disrupted first line of defense and certain degree of immunodeficiency. It is important for treating physicians to keep this micro-organism in their differential list of potential lethal microbes when assessing drug abusers and alcoholics with skin ulcer and soft tissue infection.

\section{Conclusion}

We report an autopsy case of skin and soft tissue infection, peritonitis and bacteremia due to Shewanella putrefaciens infection in a drug abuser. It signifies the importance for the physicians to keep this micro-organism in their list of potential lethal microbes when evaluating and treating drug abuser and alcoholics with skin and soft tissue infection. 


\section{References}

[1] Holt, H.M., Gahrn-Hansen, B. and Bruun, B. (2005) Shewanella algae and Shewanella putrefaciens: Clinical and Microbiological Characteristics. Clinical Microbiology and Infection, 11, 347-352. http://dx.doi.org/10.1111/j.1469-0691.2005.01108.x

[2] Pagani, L., Lang, A., Vedovelli, C., Moling, O., Rimenti, G., Pristera, R. and Milan, P. (2003) Soft Tissue Infection and Bacteremia Caused by Shewanella putrefaciens. Journal of Clinical Microbiology, 41, 2240-2241. http://dx.doi.org/10.1128/JCM.41.5.2240-2241.2003

[3] Bulut, C., Ertem, G.T., Gökcek, C., Tulek, N., Bayar, M.A. and Karakoc, E. (2004) A Rare Cause of Wound Infection: Shewanella putrefaciens. Scandinavian Journal of Infectious Diseases, 36, 692-694. http://dx.doi.org/10.1080/00365540410022620

[4] Gurdal, Y., Aydin, K., Betkas, D., Caylan, R., Caylan, R. and Koksal, I. (2007) Cerebellar Abscess and Meningitis, Caused by Shewanella putrefaciens and Klebsiella pneumoniae, Associated with Chronic Otitis Media. Journal of Medical Microbiology, 56, 1558-1560. http://dx.doi.org/10.1099/jmm.0.47044-0

[5] Jorens, P.G., Goovaerts, K. and Ieven, M. (2004) Shewanella putrefaciens Isolated in a Case of Ventilator-Associated Pneumonia. Respiration, 71, 199-201. http://dx.doi.org/10.1159/000076686

[6] Yim, S.Y., Kang, Y.S., Cha, D.R., Park, D.W., Youn, Y.K., Jo, Y.M., Kim, J.Y., Song, J.W., Sohn, J.W., Cheong, H.J., Kim, W.J., Kim, M.J. and Choi, W.S. (2010) Fatal PD Peritonitis, Necrotizing Fasciitis, and Bacteremia Due to Shewanella putrefaciens. Peritoneal Dialysis International, 30, 667-669. http://dx.doi.org/10.3747/pdi.2010.00084

[7] Vignier, N., Barreau, M., Olive, C., Baubion, E., Theodose, R., Hochedez, P. and Cabie, A. (2013) Human Infection with Shewanella putrefaciens and S. algae: Report of 16 Cases in Martinique and Review of the Literature. The American Journal of Tropical Medicine and Hygiene, 89, 151-156. http://dx.doi.org/10.4269/ajtmh.13-0055

[8] Rosai, J. (1998) The H\&E Technique: Old Mistress Apologue. Pathologica, 90, 739-742.

[9] Tsai, T.H. and You, H.Y. (2006) Necrotizing Fasciitis Caused by Shewanella putrefaciens in a Uremic Patient. Journal of Microbiology, Immunology and Infection, 39, 516-518.

[10] Chen, Y.S., Liu, Y.C., Yen, M.Y., Wan, J.H., Wang, J.H., Wann, S.R. and Cheng, D.L. (1997) Skin and Soft-Tissue Manifestations of Shewanella putrefaciens Infection. Clinical Infectious Diseases, 25, 225-229.

[11] Tsai, M.S., You, H.L., Tang, Y.F. and Liu, J.W. (2008) Shewanella Soft Tissue Infection: Case Report and Literature Review. International Journal of Infectious Diseases, 12, e119-e124. http://dx.doi.org/10.1016/j.ijid.2008.03.020

[12] Potula, R., Haorah, J., Knipe, B., Leibhart, J., Chrastil, J., Heilman, D., Dou, H., Reddy, R., Ghorpade, A. and Perisky, Y. (2006) Alcohol Abuse Enhances Neuroinflammation and Impairs Immune Response in an Animal Mode of Human Immunodeficency Virus-1 Encephalitis. American Journal of Pathology, 168, 1335-1344. http://dx.doi.org/10.2353/ajpath.2006.051181

[13] Happel, K. and Nelson, S. (2005) Alcohol, Immunosuppression, and the Lung. Proceedings of the American Thoracic Society, 2, 428-432. http://dx.doi.org/10.1513/pats.200507-065JS 